\title{
EBXML - OVERVIEW, INITIATIVES AND APPLICATIONS
}

\author{
António Pereira, Frederico Cunha, Pedro Malheiro, Américo Azevedo \\ Inesc Porto, FEUP - Faculdade de Engenharia \\ Universidade do Porto \\ Rua Roberto Frias S/N, 4200-465 Porto, Portugal \\ e-mail: \{ee01260,ee01069,ee0113,ala\}@fe.up.pt
}

\begin{abstract}
This paper describes ebXML. It gives an overview on its background and architecture, approved under the ISO/TS 15000. It also analyzes implementations of the standards' modules as well as initiatives concerning its development and adoption. Other frameworks' efforts on convergence with ebXML are discussed as well as expectations on its place in the future for electronic business.
\end{abstract}

\section{INTRODUCTION}

The globalization of the business markets brought new opportunities for business and business collaborations. Discovering the most suitable partners will give any company an advantage on its business. However, how can different enterprises, spread worldwide, overcome geographical and cultural differences, find each other and initiate business transactions?

The Internet can now connect virtually every place on the globe therefore the challenge is to provide a framework that would be widely accepted throughout all business areas.

Initially, numerous organizations decided to develop new frameworks to connected their businesses and allow an electronic base for their networks. The most successful, at a point, was Electronic Data Interchange (EDI) which had a number of problems. From the need for a private network and its high implementation costs to the fact that it was not horizontally used as the common framework throughout companies around the world, EDI had disadvantages that kept it from a wider implementation (Mertz, 2001).

With the appearance of XML, during the 1990s, the technology rapidly was adopted in various areas due to its high simplicity, flexibility, extensibility and ubiquity (R. Glushko \& J. Tenenbaum \& B. Meltzer, 2007). The Organization for Advancement for Information Standards (OASIS) - a non-profit organization that develops, encourages and supports information standards - and the United Nations body for Trade Facilitation and Electronic Business (UN/CEFACT) decided to join forces and create a new framework for electronic business using the general-purpose extensible Markup Language: ebXML. Apart from the known influence of the UN/CEFACT, OASIS' decisions have, as well, great influence on the definition of used standards around the world as it has more than 600 organizations as members, namely SUN Microsystems, SAP, IBM, Primeton, EDS and BEA Systems, Inc.. Both the needs for uniformity and convergence of the dispersed and often competing efforts of many organizations to create electronic business frameworks led to the decision 
of creating ebXML. The vision of ebXML's founders was to enable enterprises of any size, in any global region, to conduct business using the Internet (ebXML, 2007).

After the release of the OASIS approved standards, the International Standard Consortium Technical Committee (ISO/TS) followed. In spite of this, work in improvements and development is ongoing, in a fast rate as the standards' adoption.

This article will make an overview on the ebXML's concepts followed by examples of actual implementations. Initiative concerning the growth of the framework will be presented, making the link to the final discussion on what to expect in the future for business networking.

\section{2. ebXML CONCEPTS AND ARCHITECTURE}

The ebXML Work Group has developed architectural modules that cover all areas needed to ensure reliable and global interoperability among businesses. These Standards were developed by ebXML Technical Committees and, in 2004, approved by ISO and published as technical specifications ISO/TS 15000. Each part of the ISO specifies one of the modules of ebXML's suit of standards.

\section{1. ebXML Specifications and ISO/TS 15000 Standard}

The standard covers only five of the frameworks' elements: Collaboration protocol Profiles and Agreements (which will be presented in more detail than the others for it is key to understand the framework's objective and how it works), Messaging Service, Registry Information Module, Registry Services Specification and Core Components.

The main purpose of the module described under ISO 15000-1, is, basically, to specify how companies do business. Each company must create their own Collaboration Protocol Profile (CPP). Here lie descriptions of the business capabilities of an individual party, how it exchanges information, how its business processes are and what kind of relations it's interested in engaging. Figure 1 exemplifies how a CPP is built.

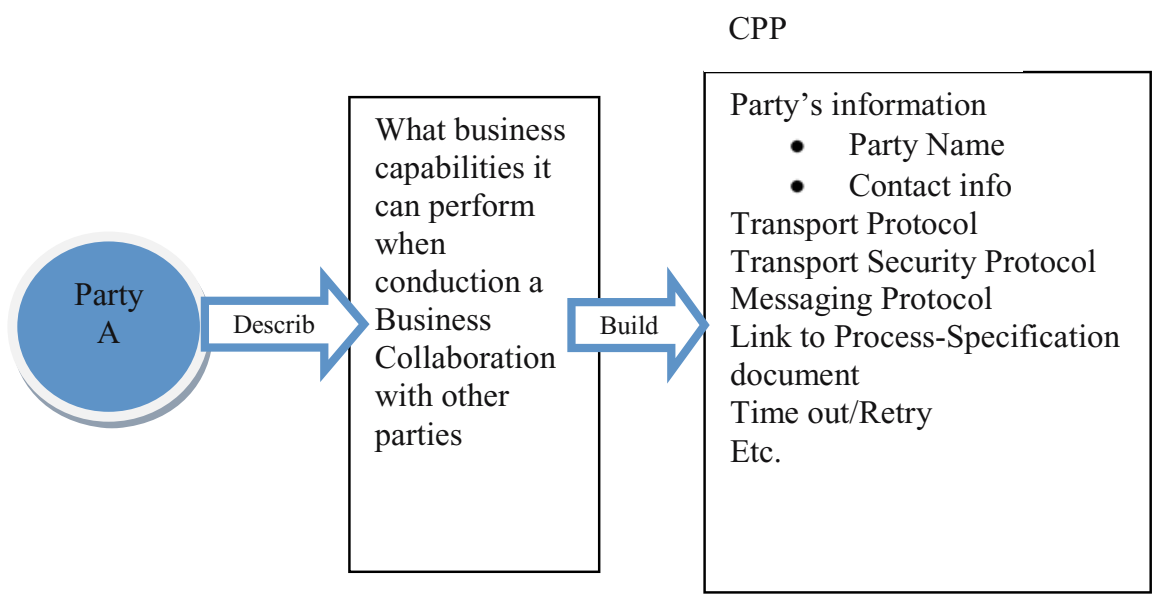

Figure 1. Steps a company must take to build its CPP

By specifying the enterprise's business needs and capabilities in a universal form (XML), the process of searching for suitable business partners is greatly simplified. With 
a common database storing all the CPPs, a simple query will identify any company compliant with the desired restrictions. A company can file multiple CPPs with the registry, thus expecting to create various business agreements.

When compatible CPPs are found, a Collaboration Protocol Agreement (CPA) is automatically created. This CPA describes the form in which the business collaboration will occur, the type of messages being sent and how. To clarify the concept, if a CPP declares "Company A can do X", a CPA will then define "Company A and B will do X together" (Mertz, 2001). Figure 2 shows how two parties' CPPs are negotiated into a CPA.

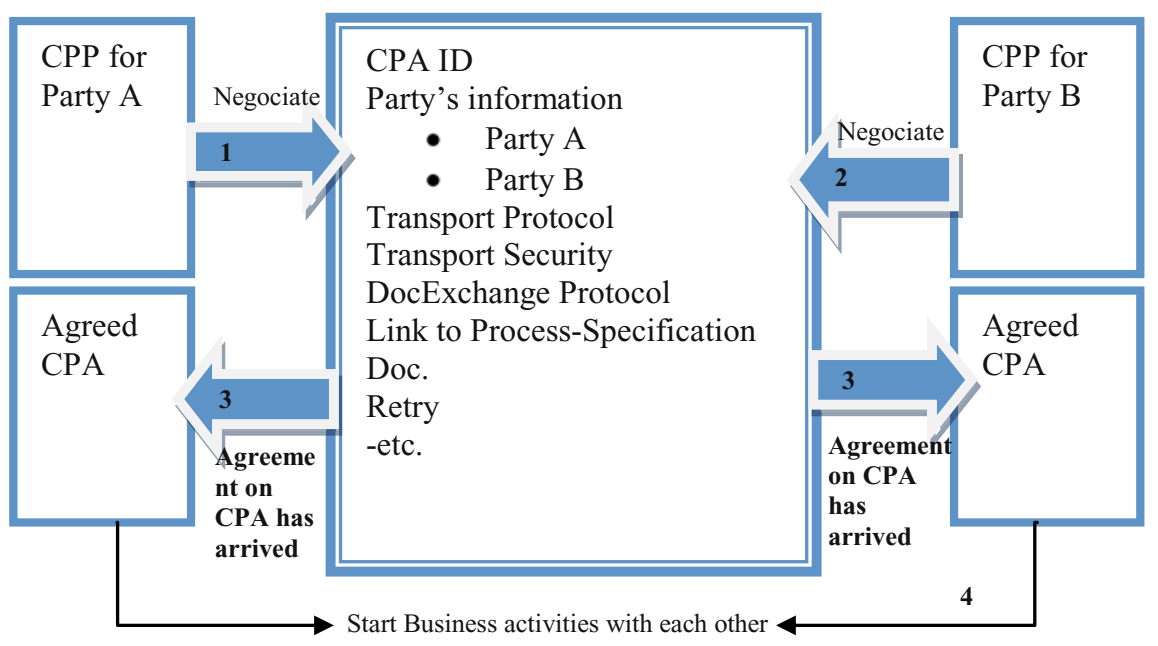

Figure 2. The creation of a CPA through CPPs

Once a CPP is filed, it cannot be changed for this action would put in risk all the CPAs previously created.

Described in the ISO/TS 15000-2 is the ebXML Messaging Service module version 2.0 .

In order to enable the actual information exchange between enterprises, security and reliability are critical factors, especially considering that the communications may be made through means as unsecure as the Internet. To overcome this issue a XML based messaging service was designed so it would be robust and simple to use on enterprises' trading messages. To perform as a universal framework, it runs over various communication protocols such as HTTP, SMTP and FTP. Never forgetting the top goal of being a framework available to everyone, its XML-based characteristic allowed it to be a low-cost solution, when compared with existing EDI solutions. The ebMS enveloping not only makes the message secure but it also allows transfer of both XML-based and non XML-based data, covering all cases where additional information is part of the business. This is possible through ebMS's flexibility and independence of the actual payload being sent. Recently a new version, v3.0, of ebMS was approved by OASIS although v2.0 is still the most used.

The third module of the standard, ISO/TS 15000-3, is the specification of the Registry Information Model. A secure information repository, the Registry, where information accessible to everyone is one of the core features of the ebXML framework. 
Sharing enterprises' CPPs will allow any other company to easily locate compatible business partners. Additionally, the availability of the registry allows the integration of any new enterprise in the ebXML system through a simple submission of its CPP. Apart from searching and submitting, the database also allows enterprises such operations as managing, retrieving and removing, all made through the registry interface. Storage in the registry is not limited to XML schemas and documents, it also supports submission of UML models and software components (ISO/TS 15000-3, 2004).

The registry is responsible not only for the storage but also for the safekeeping of all its information, which simplifies enterprises' operations but, on the other hand, enhances the database's needs in security issues. Registry Information Model specification was approved under the ISO/TS 15000 Part 3 in 2004 although it was already widely used as an OASIS approved standard.

The ISO/TS 15000 Part 4 defines how communications with the registry are made. All the services provided by the registry are also described in normative form. To better distinguish, ebRIM provides a High level, conceptual definition of what the registry is and how it works, while the ebRS contains detailed and technical information on how every operation designed by the ebRIM is performed.

One of its most important functions is to regulate the users' access to the registry. Who can perform which operations and how must be well defined with the ebRS. In addition to this, by applying all these rules to the Registry, security level within the ebXML system is greatly raised.

The 5th and final part of the ISO/TS 15000 standard, entitled "Core Components Technical Specification" addresses the difficulty of connection and interoperability between different software. By following this standard, applications will be able to understand each others' business semantics thus enabling information exchange between different enterprises, governmental agencies or any other kind of organization. It is not a standard for a specific business area, therefore it can, in fact, be applied in any environment where business information exchange is required. "ISO/TS 15000-5:2005 will form the basis for standards development work of business analysts, business users and information technology specialists supplying the content of and implementing applications that will employ the UN/CEFACT Core Component Library (CCL)" (ISO/TS 15000-5, 2005).

Another specification of ebXML not found in the ISO/TS 15000 but developed by OASIS is the Business Process Schema Specification (BPSS). It's used to describe standard B2B business processes by defining choreography of activities amongst business partners. It usually refers to standard business documents that are exchanged in the business process.

\subsection{Use Case Example}

The first step for an enterprise, willing to integrate in the ebXML system should be to question the registry for documentation regarding Core Library, i.e., information on how it can initiate its own ebXML implementation. After creating a standard CPP, company A must file it with the ebXML registry for sharing, storing and safekeeping. This action will fully integrate the company in the ebXML framework, enabling it to query the database for compatible CPPs.

Once two (or more, if the business process was defined like that) compatible CPPs are found, a CPA is automatically created, which defines collaborative specifications between the parties.

After this point, actual business transactions are completely set-up, leaving only legal restrictions to finalize, which are obviously outside the ebXML's range of competencies. 
Figure 3 shows this sequence of steps taken by a company, in order to do business through the ebXML framework,

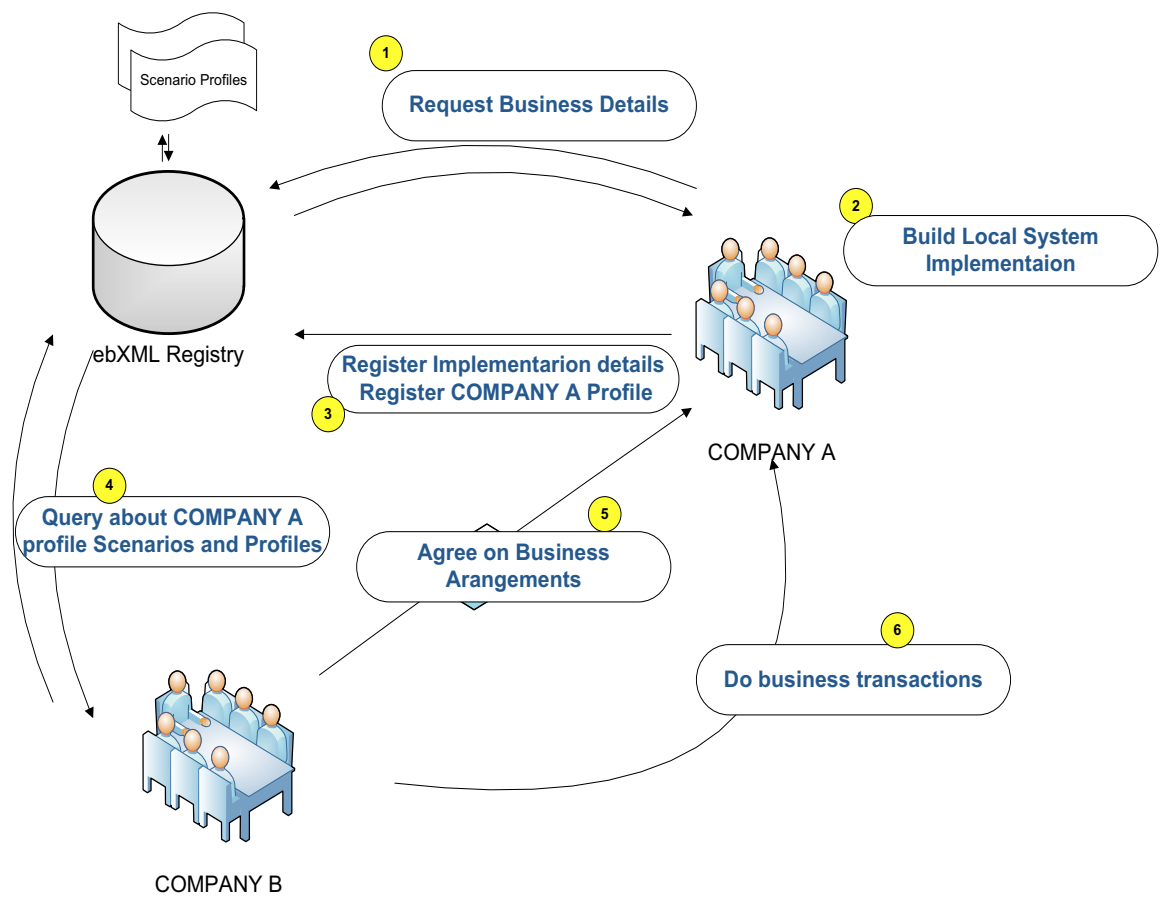

Figure 3. ebXML use case scenario

\section{INITIATIVES AND APPLICATIONS}

Nowadays, ebXML standards are adopted by many companies. In the majority of the cases just part of the standards are implemented. Some companies try to use ebXML parts as plug-ins on their existing solutions. Others try to redesign their architecture for using the ebXML standards.

In any case, and due to its success in enterprise integration and interoperability in collaborative businesses, several research projects and technology infrastructures based on ebXML are appearing (Chituc \& Azevedo, 2006).

As the ebXML specifications mature and are upgraded, its use is extended to even more areas, thus heading to the ebxml's vision.

\section{1. ebXML - A Generic Framework}

Although it was originally designed to support electronic business, ebXML is a generic framework for collaboration between several entities. "It is equally suited to eGovernment and e-Health integration as it is for e-Commerce" (van der Eijk, 2007). 
ebXML is being deployed worldwide: in the Agriculture, Chemical, Telecommunications and Automotive Sectors, in Governments and Healthcare Services and in non-government organizations, Universities and Research Centers. Next are briefly exposed some deployments where this generic framework was adopted: in a Japanese food retail industry, in the Norwegian Healthcare Service and in a German mobile communications company.

The Kasumi B2B Integration Project is an initiative in the Japanese food retail industry that aims to augment the added value of services instead of improving efficiency by automating processes. This project develops communication protocols for real B2B collaborations. The adoption of Internet $\mathrm{B} 2 \mathrm{~B}$ standards reduces the costs needed to develop solutions for B2B collaboration. This project is one of many to use ebXML MS module as a communication protocol for messaging over the Internet.

Kasumi runs a supermarket chain and has several business partners. The aiming at augmenting added value of services improves the quality of information exchange and therefore provides benefits to suppliers and retailers.

A key advantage of using ebMS to enable B2B collaboration is that it doesn't demand a highly developed infrastructure (Hayashi \& Mizoguchi, 2003).

Fig. 4 shows an example of an ebXML document exchange between a retailer and a manufacturer from the Kasumi project. This is a XML document that a supplier would send to a retailer when requesting product registration (the information in the document can be of one or more products). The retailer accesses the document through a web page and a negotiation between the two parties occurs through phone or e-mail. Finally the document is updated, stored in the database and sent back to the supplier.

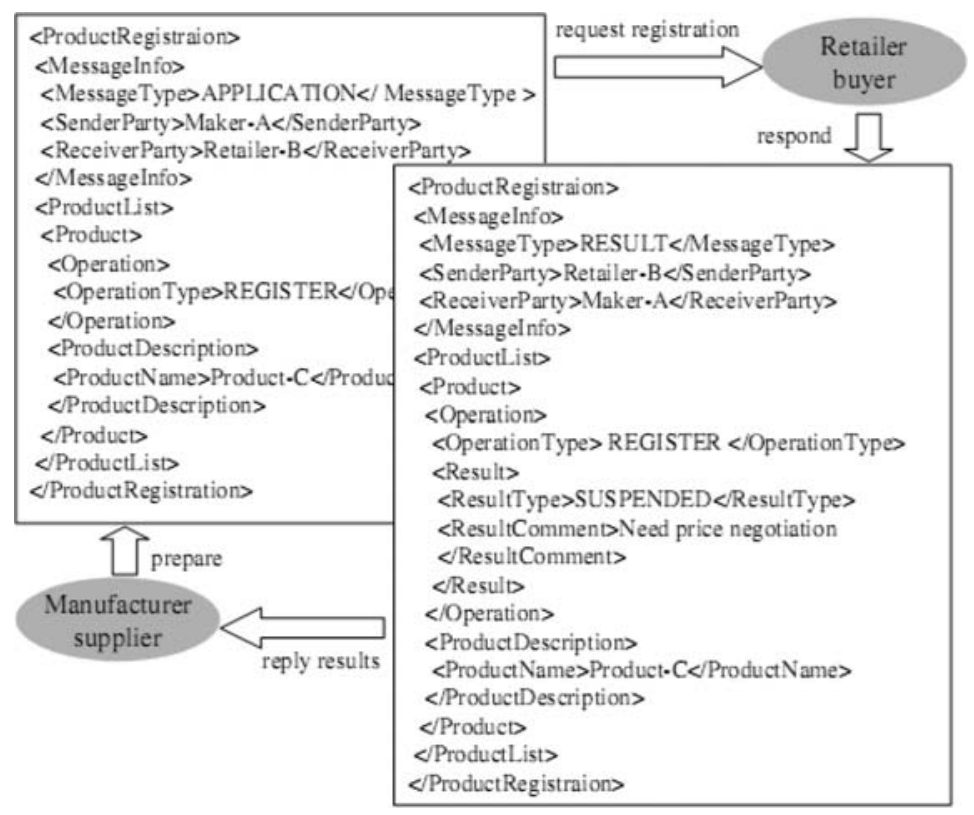

Figure 4. ebXML document used in Kasumi

A second example is the Norwegian Healthcare Service. It's managed by the National Insurance Administration (NIA) of Norway. The Healthcare Service had an EDI-based communications infrastructure between the NIA and their business partners: pharmacies, hospitals and general practitioners. 
But the NIA decided that an upgrade was necessary. The main reasons for this upgrade were the security and reliability of the messages as well as increasing the administrative processes which led to a better service provided and reduced manual handling.

Another issue in the upgrade was the choice of using open standards solutions in the new architecture. The NIA and her partners chose the ebMS standard for their message transport protocol, mainly due to the secure and reliable messaging of arbitrary payloads that it provides.

The main reason for using open standard solutions is the level of interoperability it allows. The responsibility of implementing these standards is strictly of the business partners. In fact, each one can implement its own solution, one that suits their business requirements, with the only concern that the solution uses the chosen standards. (van der Eijk, 2005)

Another example of ebXML's application is T-Mobile Communications Company. This is a German company that has business collaboration with suppliers, distributors, wholesales, customers and other business partners involved in the supply-chain. Their business interactions create large amounts of information and, therefore, massive exchanges of messages. A main concern of T-Mobile, when selecting the $\mathrm{B} 2 \mathrm{~B}$ standard to use, was for the overall system to have a more capable and standard-based B2B interface that would work for all business domains. Other requirements concerned the ability to exchange business data in any format, in a reliable and secure way among the several parties, using open standard solutions. T-Mobile found in ebXML MS and ebXML CPP/A the solution that best met their requirements. One key advantage that T-Mobile noted with their overall experience while using ebXML was, that besides being a powerful tool, at the same time it was very easy to implement and to integrate in existing enterprise applications with limited, or even no changes, to back-end solutions.

By deploying a generic solution for business collaboration, T-Mobile facilitates future connections to new partners (van der Eijk, 2007).

\section{2. ebXML's Adoption by RosettaNet}

More and more solutions are developing their standards adopting or approaching to ebXML due to the generic and simplicity nature of its use. So, these adoptions of ebXML standards aim at a better final solution.

In 2001, the widely known RosettaNet announced that future versions of RosettaNet Implementation Framework (RNIF) would include support for ebXML Messaging Service Specification. RNIF serves as a guide for e-business process development and implementation and, by supporting ebMS, hopes to achieve interoperability goals across industries. This way, RosettaNet ensures that their vertical supply-chain standards are supported by a horizontal, universally accepted messaging service (RosettaNet press release, 2007).

In 2003, RosettaNet formally adopted ebXML BPSS for expressing business collaborations involving RosettaNet PIPs (OASIS news, 2003). RosettaNet used an error prone manual for configuration, but now their software can install BPSS schemas and be configured correctly on the first try.

RosettaNet's configuration of the system connectivity contains information about the identity of their partners, security certificates and network endpoints. The exchange of this information is done in an informal manner (e.g. e-mail exchanges). Here the ebXML CPP/A can be adopt to automate all the process, reduce error and make the exchange of information easier (Jauhiainen \& Lehtonen \& Ranta-aho \& Rogemond, 2006). 


\section{3. freebXML}

freebXML is an initiative that promotes the growth, development and adoption of ebXML technologies and software solutions. The objective of freebXML.org is to be a center for information sharing and a repository of 'free' ebXML code and applications (freebXML, 2007).

freebXML.org is sponsored by the Center for E-Commerce Infrastructure Development and the Department of Computer Science \& Information Systems at the University of Hong Kong. It has several projects: ebMail, freebXML BP, freebXML CC, freebXML Registry, Hermes Message Service Handler and Webswell Connector. Next is a briefly description of three of these projects:

ebMail is a Graphical User Interface (GUI) system that enables users with limited knowledge of ebXML to engage in B2B activities. The user interface is an ebMS-based mail client that allows communications with business partners. The messages exchanged are read in a GUI form which makes it simple to use and with no requirements concerning integration. Plug-in modules provide excellent flexibility and extensibility for adding new business document types and to incorporate advanced functions.

freebXML BP is the project name for the ebBP Editor tool. This tool was designed for helping the user in creating business process specification based on BPSS. This project is realized within the scope of IST-2103 Artemis project supported by the European Commission, DG Information Society and Media, eHealth Unit. The ebBP Editor implementation is based on an XML Schema Editor and is this editor that creates the XML segments of BPSS.

Hermes is a Message Service Handler that provides standardized, reliable and secure infrastructure for exchanging business documents. It uses the ebMS standard and supports secure messaging functions through Internet-based technologies and transport protocols to suit different needs and business requirements. Hermes has been successfully deployed and is being used by two enterprises (a buyer and a seller of office supplies) in Hong Kong.

\section{CONCLUSIONS}

Today, CEOs face numerous problems while trying to increase their enterprises' markets from which standards to use for deploying the business solution to the level of information shared between partners. All agree that, in order to broaden businesses markets, there are common requirements for the solutions. An electronic mean for displaying business processes in a simpler and less expensive way for inter-integration, as well as ways for supporting and represent business processes independently from technical solutions.

Previous frameworks specified separate and incomplete solutions. EDI provided a runtime data structure, routing specification tools, but didn't provide support for bilateral negotiations, business process modeling or APIs. The universal standard XML is not a communications solution, doesn't define business semantics and doesn't have a transaction registry. Web Services Description Language (WSDL), provides simple ways for identifying services' name, their parameters and identifies Business Processes. As seen before in this article, ebXML provides tools and methods to address these issues.

Limitations still exist in the ebXML standard. It does not provide support for runtime alterations on CPP \& CPA. Human decisions are still not directly integrated in the framework. 


\subsection{Expectations}

Business-to-Business integration, by electronic means, will continue to increase, as will the need for higher levels of interactions. The development of new tools and methods is dependent from this increase. To support these increases and the adoption of e-business, ebXML has been considered for native integration within Linux, through organizations such as the Open Source Development Lab (OSDL). "The rapid acceptance of LINUX worldwide and especially in high growth countries such as China, India and Japan, should fuel dramatic growth in the ebXML infrastructure" (Webber, 2007). The development of uniform infrastructures for sharing information between the front-office and the backoffice, will also lead to a rapid adoption of ebXML in business model. In the near future, ebXML will provide methods for implementing Radio Frequency Identification (RFID) and mobility through wireless solutions. These methods will always be based upon the core definitions of ebXML. ebMS module will continue to evolve, enabling new tools for system designers to deliver a higher quality of service at a greater logical level. 


\section{REFERENCES}

1. Campbell, S. "ebXML technology”, January-February 2006.

2. Chituc, C.-M., Azevedo, A.L. "Business Networking - the Technological Infrastructure Support." In Knowledge and Technology Management in Virtual Organizations, Putnik, G., Cunha M. ed., Chapter 16, 2006, Idea Group Publishing, pp. 334-353.

3. ebXML, http://www.ebxml.org

4. freebXML, 2007. Available online at: http://www.freebxml.org/ (accessed December 10, 2007).

5. Frømyr, J. "The users of ebXMLWho is using ebXML - a review of the global adoption of ebXML." Presentation at the CEN/ISSS ebXML Market Survey Event Lisbon, February 1, 2006.

6. Hayashi, K., \& Mizoguchi, R. (2003). Document Exchange Model for Augmenting Added Value of B2B Collaboration. Available online at: http:/www.ei.sanken.osakau.ac.jp/pub/miz/ICED_CR_submit hayashi 3.pdf (accessed October 15, 2007).

7. ISO/TS 15000, International Standards Organization, 2005

8. Jauhiainen, S., Lehtonen, O., Ranta-aho, P., Rogemond, N., 2006. Available online at: http://www.soberit.hut.fi/T-86/T-86.161/2005/B2Bi-final.pdf (accessed December 10, 2007).

9. Maijala, V. "MASTER'S THESIS Outlook of Information Security in E-Business”. February 17, 2004.

10. Mertz, D., 2001. "Understanding ebXML". Available online at: http://www.ibm.com/developerworks/xml/library/x-ebxml/. (accessed November 9, 2007).

11. OASIS news, 2003. Available online at: http://www.oasis-open.org/news/oasis_news_10_20_03.php (accessed November 30, 2007).

12. OASIS. http://www.oasis-open.org

13. Pigaga, A.. "Business Process Modeling Using ebXML: Case Study". In http://www.sts.tu-harburg.de/pwand-m-theses/2003/piga03.pdf. May, 2003

14. Pro, S. "What is ebXML" In Presentation at the CEN/ISSS ebXML Market Survey Event Lisbon, February 1, 2006.

15. Robert J. Glushko, Jay M. Tenenbaum and Bart Meltzer "An XML framework for Agent-based Ecommerce". In "Communications of the ACM", Vol.3, No3, March 1999

16. RosettaNet press release, 2001. Available online at: http://www.rosettanet.org/cms/sites/RosettaNet/News/PressReleases/2001/modules/rn_news/rn_news_001 1.html (accessed December 10, 2007).

17. Shin, Sang - ebXML Presentation. In http://www.javapassion.com/webservices/, April, 2004

18. Tellmann, R., \& Maedche, A. "Analysis of B2B Standards and Systems" Version: 1.3, February 28, 2003

19. van der Eijk, P. (2005). Norwegian e-health infrastructure based on XML, ebXML and PKI: Trygdeetaten case study. Available online at: OASIS, http://www.oasis-open.org/casestudies/Trygdeetaten-A4.pdf (accessed November 4, 2007).

20. van der Eijk, P. (2007). T-Mobile International ebXML B2B Gateway Solution: Adoption of the ebXML Messaging Service and ebXML Collaboration Protocol Profiles and Agreements OASIS Standards. Available online at: OASIS, http://www.oasis-open.org/casestudies/tmobile-A4.pdf (accessed December 10, 2007).

21. Webber, D., 2007. "The Benefits of ebXML for e-Business". Available online at: http://www.idealliance.org/proceedings/xml04/papers/44/webber.htm. (accessed November 10, 2007). 